\title{
Study on Flood and Sediment Joint Operation of Dadu River Downstream Cascade Reservoirs
}

\author{
Liyu $\mathrm{Lu}^{1}$, Chunhua Tao ${ }^{2, \mathrm{a}}$ and Weibin Huang ${ }^{3}$ \\ ${ }^{1}$ College of Architecture and Civil Engineering, Xihua University, Chengdu 610039, China \\ ${ }^{2}$ Dadu River Hydropower Development Co., Ltd., Chengdu 610041, China \\ ${ }^{3}$ College of Water Resource and Hydropower, Sichuan University, Chengdu 610065, China
}

\begin{abstract}
There is large amount of high hardness sand in the water flow in Dadu river. The problem of sediment deposition is very prominent in the two early reservoirs, Gongzui reservoir and Tongjiezi reservoir. In order to decrease sediment deposition effectively and extend the service life of them, the sediment characteristics of Dadu river cascade hydropower stations are analysed, as well as changes of sediment deposition in Gongzui reservoir and Tongjiezi reservoir after Pubugou reservoir puts into operation. Flood forecast and pre-discharge operation theory are studied for utilizing the discarding water to improve sediment-flushing effect, and flood and sediment joint dispatching schemes of cascade reservoirs are proposed. In order to evaluate effects of joint dispatching schemes, SBED extended one-dimensional flushing sediment mathematical model of deposited reservoir is built, and the mathematical model is used for simulative computation of coming 20-years sediment-flushing effect. After that, the effects of different schemes are analyzed comparatively. Three conclusions can be drawn from the studying. Firstly, the sediment in Gongzui reservoir and Tongjiezi reservoir is obviously reduced after Pubugou reservoir puts into operation. Secondly, flood forecast, pre-discharge operation theory and creating sand-flushing conditions can obviously improve sediment-flushing effects and avoid wasting power generation water when the water levels and outflows of Pubugou reservoir, Gongzui reservoir and Tongjiezi reservoir are rationally controlled. Finally, the larger the inflows and the lower the water level of Gongzui reservoir and Tongjiezi reservoir is, the more obvious the sediment-flushing effects are. According to situations of power plant at the time, such as rules of flood controlling and operation requirements of flood discharge facilities, it is recommended that the inflow of Gongzui reservoir is controlled at about $4500 \mathrm{~m}^{3} / \mathrm{s}$, and timely lower the water levels of Gongzui reservoir and Tongjiezi reservoir to their dead water levels, when carrying out joint dispatching schemes.
\end{abstract}

\section{Introduction}

Dadu River is located in the midwest regions of Sichuan Province in China, and originated in Qinghai Province. It is the largest tributary of the Minjiang river with total length $1062 \mathrm{~km}$ and basin area $77400 \mathrm{~km}^{2}$ excluding Qingyijiang river. Water losses and soil erosion is not serious in the upper reaches of Dadu river, annual average modulus of sediment runoff is $164 \mathrm{t} /\left(\mathrm{km}^{2} \cdot \mathrm{a}\right)$. Soil erosion is serious in the middle reaches with modulus 16704t/ $\left(\mathrm{km}^{2} \bullet \mathrm{a}\right)$. Because of good condition of ground integrity and vegetation, water losses and soil erosion is not serious in the lower reaches ${ }^{[1]}$.

In the 1970s and 1990s, Gongzui and Tongjiezi hydropower station were put into operation separately, both located in the downstream of the river. Another two stations, Pubugou and Shenxigou hydropower station in the middle reaches began to operate in 2009 and 2010. Pubugou reservoir is the only multi seasonal regulating reservoir, and its sand blocking capacity can effectively block most of the sand from upstream and midstream. Before Pubugou reservoir puts into operation, the problem of sediment deposition of Gongzui reservoir and Tongjiezi reservoir is becoming more and more serious for the large amount of sand. As of 2009, the total sediment deposition of Gongzui reservoirs is 250.18 million $\mathrm{m}^{3}$, accounting for $66.95 \%$ of the total capacity. $18.31 \%$ of the adjustment capacity is lost ${ }^{[2]}$. The total sediment deposition of Tongjiezi reservoir is 132.18 million $\mathrm{m}^{3}$, about $62.44 \%$ of the total capacity, and $8.97 \%$ of the regulation capacity is lost. To some extent, the serious sediment deposition of reservoirs is affecting the safety of the reservoirs and generator units operation.

\section{Analysis of the amount of sand in inflow of Gongzui and Tongjiezi reservoir after Pubugou reservoir impoundment}


After Pubugou reservoir impoundment, bed load and most of the suspended sediment above over the dam are stored in the reservoir. Because Shenxigou is a runoff reservoir, we can ignore its role of sand blocking. Therefore, the sediment of Gongzui reservoir is composed of the sediment discharged from the Pubugou reservoir and the sand from Pubugou-Gongzui section.

The ration of total capacity and annual sediment of Pubugou reservoir is 191, reservoir service life will be long when only sedimentation is considered. According to the simulation results, after 50 years' operation, the total deposition volume of Pubugou reservoir will be 1.11 billion $\mathrm{m}^{3}$, the blocking ratio of suspended sediment will be $86.5 \%$, and annual average sediment concentration of outflow water $112 \mathrm{~g} / \mathrm{m}^{3}$. Meanwhile, the deposition will cause 595 million $\mathrm{m}^{3}$ loss of adjustment capacity with loss ratio $14.3 \%$. Remaining adjustment capacity will be 3.24 billion $\mathrm{m}^{3}$. After 100 years' operation from now, the total deposit volume of Pubugou reservoir will be1.86 billion $\mathrm{m}^{3}$, the blocking ratio of suspended sediment will be $85.9 \%$, and annual average sediment concentration of outflow water $120 \mathrm{~g} / \mathrm{m}^{3}$. Meanwhile, the deposition will cause the adjustment capacity loss of 960 million $\mathrm{m}^{3}$,or $25.0 \%$. Then the remaining adjustment capacity will be 2.88 billion $\mathrm{m}^{3}$. As shown in Table 1 .

Table 1. The calculation result of Pubugou reservoir sediment deposition

\begin{tabular}{|c|c|c|c|c|c|}
\hline $\begin{array}{l}\text { Running time } \\
\text { length } \\
\text { (years) }\end{array}$ & $\begin{array}{l}\text { deposit volume } \\
\text { ( billion } \mathrm{m}^{3} \text { ) }\end{array}$ & $\begin{array}{l}\text { deposit volume of } \\
\text { adjustment capacity } \\
\left(\text { million } \mathrm{m}^{3}\right)\end{array}$ & $\begin{array}{c}\text { Loss ratio of } \\
\text { adjustment capacity } \\
(\%)\end{array}$ & $\begin{array}{c}\text { blocking ratio of } \\
\text { suspended sediment } \\
(\%)\end{array}$ & $\begin{array}{c}\text { annual average } \\
\text { sediment } \\
\text { concentration of } \\
\text { outflow water } \\
\left(\mathrm{g} / \mathrm{m}^{3}\right)\end{array}$ \\
\hline 20 & 0.43 & 254 & 5.28 & 86.8 & 110 \\
\hline 50 & 1.11 & 595 & 14.3 & 86.5 & 112 \\
\hline 100 & 1.86 & 960 & 25.0 & 85.9 & 120 \\
\hline
\end{tabular}

In the first 100 years of Pubugou reservoir operation, blocking ratio of suspended sediment is within the range of $85.9 \% \sim 86.8 \%$, with minor change. Particle size of suspended sediment in the outflow is $0.025 \mathrm{~mm}$. In natural condition, the annual average sediment-transportation of suspended sediment is 31.70 million tons at the dam site of Pubguou hydropower station, and 37.5 million tons at the dam site of Gongzui hydropower station. 100 years later, considering the blocking sediment ratio of Pubugou reservoir to be $85 \%$, the annual average sediment-transportation of suspended sediment in outflow will be 4.76 million tons at the dam site of Pubguou hydropower station. Taking sediment from Pubugou-Gongzui section into consideration, 5.80 million tons, the annual average sediment-transportation of suspended sediment is 10.60 million tons at the dam site of Gongzui hydropower station ${ }^{[3]}$.

\section{Study on flood and sediment joint dispatching schemes}

\subsection{General joint dispatching schemes}

Since Gongzui hydropower station and Tongjiezi hydropower station put into operation, erosion and deposition have reached a balanced state. Their dead storages have basically lost because of the sediment deposition, more and more sediment goes into hydroturbine units, and it is threatening the normal operation of the hydropower stations. In order to slow the sediment deposition of Gongzui reservoir and Tongjiezi reservoir, the current scheme is lowering the water level of the two reservoirs to reduce deposition when the inflow increasing. Pubugou reservoir lies in the upper reaches of Gongzui reservoir and Tongjiezi reservoir. It was put into operation in 2009. Because it has regulation and storage capacity and with function of sand blocking, the amount of sediment entering Gongzui reservoir and Tongjiezi reservoir is substantially reduced. A chance is provided for moderately raising the water level of these two reservoirs. If the flood and sediment joint dispatching scheme is suitable, not only may it be avoided that raised operation water level aggravates the deposition, but also the flushing effect can be improved and part of the capacity of these two reservoirs be recovered.

(1)Timing of sand sluicing joint dispatching

Sand sluicing joint dispatching is an effective way of creating suitable conditions to reduce the sediment deposition.

The water level requirements of Pubugou reservoir: when the water level of Pubugou reservoir is up to $841 \mathrm{~m}$ (the flood controlling limited level) or other water level limit, the abandoned water can be used to improve the sand sluicing effect of Gongzui reservoir and Tongjiezi reservoir. What's more, sand sluicing joint dispatching can avoid wasting the power generation water by forecast and pre-discharge, for the water which discharged can be supplemented by impounding flood.

The water level requirements of Pubugou reservoir, Gongzui reservoir and Tongjiezi reservoir: when the floods is coming and the inflow is approximately equal to maximum power flow, abandoning water of Pubugou reservoir in advance can be used for flushing the sediment of Gongzui reservoir and Tongjiezi reservoir in lower reaches. In order to ensure the security of the Pubugou dam, faceplate rock-fill dam, the water level decline should be less than $1 \mathrm{~m}$ every day.

In order to achieve the expected flushing effect, sand sluicing joint operation should be about 5 times every year, and each time should be about 12 hours.

(2) Flow of joint sand sluicing

According to flood controlling requirements of these 
power plants and running requirement of their flood discharge facilities, it is recommended to control the inflow of Gongzui reservoir $Q_{\text {need }}$ in the range of $4000 \mathrm{~m}^{3} / \mathrm{s}$ to $4500 \mathrm{~m}^{3} / \mathrm{s}$ to achieve good flushing effect, During the actual operation process, the inflow of Gongzui reservoir can be adjusted within this range based on flood forecast,.

The outflow of Pubugou reservoir $Q_{\text {out }}$ is equal to the inflow of Gongzui reservoir $Q_{\text {need }}$ minus the interval flow $Q_{\text {interval }}$ between Pubugou reservoir and Gongzui reservoir. The bigger the interval flow is, such as $600 \mathrm{~m}^{3} / \mathrm{s}$, the less the abandoned water will be for joint sand sluicing.

(3)The time length of joint sand sluicing

$$
t=\frac{\sum_{i=0}^{n}\left(Q_{i}-Q_{\text {power }}\right) \times T}{Q_{\text {need }}-Q_{\text {int erval }}}
$$

In the formula, $Q_{i}$ is the forecasting flood flow of
Pubugou reservoir in the $i$ period, $Q_{\text {power }}$ is the maximum power flow of Pubugou hydropower station, $T$ is the length of the period, $t$ is the time length for joint sand sluicing. It is better to control the time length to about 12 hours each time for joint sand sluicing.

(4) Operation requirements of Gongzui reservoir and Tongjiezi reservoir

In order to improve the sediment flushing effect, the water levels of Gongzui reservoir and Tongjiezi reservoir should be dropped to their dead water levels which are $520 \mathrm{~m}$ and $469 \mathrm{~m}$ seperately, and the sand-sluicing gates should be opened before the joint flushing flow reaches the dams.

\subsection{Simulation schemes of water and sediment joint dispatching}

In order to compare the effects of different water and sediment joint dispatching scheme, we educe the following schemes, see Table 2 , to simulative calculate and analyze the flushing effect.

Table 2 .The schemes of water and sediment joint dispatching

\begin{tabular}{|c|c|c|c|c|c|c|}
\hline \multirow{2}{*}{ scheme } & \multicolumn{2}{|c|}{ Pubugou Reservoir } & \multicolumn{2}{c|}{ Gongzui Reservoir } & \multicolumn{2}{c|}{ Tongjiezi Reservoir } \\
\cline { 2 - 7 } & $\begin{array}{c}\text { inflow } \\
\left(\mathrm{m}^{3} / \mathrm{s}\right)\end{array}$ & $\begin{array}{c}\text { water level } \\
(\mathrm{m})\end{array}$ & $\begin{array}{c}\text { flushing flow } \\
\left(\mathrm{m}^{3} / \mathrm{s}\right)\end{array}$ & $\begin{array}{c}\text { water level } \\
(\mathrm{m})\end{array}$ & $\begin{array}{c}\text { flushing flow } \\
\left(\mathrm{m}^{3} / \mathrm{s}\right)\end{array}$ & $\begin{array}{c}\text { water level } \\
(\mathrm{m})\end{array}$ \\
\hline scheme 1 & $\geq 2200$ & $840.3 \sim 841$ & 4000 & 520 & 4000 & 469 \\
\hline scheme 2 & $\geq 2200$ & $840.1 \sim 841$ & 4500 & 520 & 4500 & 469 \\
\hline
\end{tabular}

reservoir, annual maximum flushing amount increases by

\section{Effect analysis of water and sediment joint dispatching schemes}

In the paper, SBED extended one-dimensional flushing sediment mathematical model of deposited reservoir is built to calculate sand sluicing effect. Period, reaches of the river and sediment grain size are considered during the simulation ${ }^{[4-5]}$.

(1) Sand sluicing effect of different schemes of Gongzui reservoir

After carrying out flood and sediment joint dispatching between Pubugou reservoir and Gongzui
1.06 million $\mathrm{m}^{3}$ when flushing flow is $4000 \mathrm{~m}^{3} / \mathrm{s}$, while annual maximum flushing sediment amount increases by 2.47 million $\mathrm{m}^{3}$ when flushing flow is $4500 \mathrm{~m}^{3} / \mathrm{s}$. Flushing rate improves $7.4 \%$ and $17.2 \%$ respectively. According to a series of water and sediment simulative calculations, both existing schemes and joint operation schemes of flushing flow $4000 \mathrm{~m}^{3} / \mathrm{s}$ or $4500 \mathrm{~m}^{3} / \mathrm{s}$, sediment will be accumulatively flushed in the first 15 years of Pubugou reservoir operation, after that there will be no accumulative flushing any more. Sediment flushing effects of Gongzui reservoir for different schemes are shown in Table 3 and Figure 1

Table 3. Gongzui reservoir sediment accumulative flushing amount of different schemes

\begin{tabular}{|c|c|c|c|c|c|c|c|c|c|c|c|}
\hline \multicolumn{2}{|c|}{ year } & 1 & 2 & 3 & 4 & 5 & 6 & 7 & 8 & 9 & 10 \\
\hline \multirow{3}{*}{$\begin{array}{l}\text { accumulative } \\
\text { flushing amount }\end{array}$} & existing scheme & -527 & -599 & -682 & -704 & -787 & -1011 & -1024 & -1059 & -1054 & -1097 \\
\hline & $\begin{array}{l}\text { flushing flow } \\
4000 \mathrm{~m}^{3} / \mathrm{s}\end{array}$ & -545 & -669 & -820 & -828 & -964 & -1125 & -1155 & -1235 & -1212 & -1294 \\
\hline & $\begin{array}{c}\text { flushing flow } \\
4500 \mathrm{~m}^{3} / \mathrm{s}\end{array}$ & -567 & -695 & -865 & -871 & -1008 & -1154 & -1182 & -1278 & -1262 & -1364 \\
\hline \multicolumn{2}{|c|}{ year } & 11 & 12 & 13 & 14 & 15 & 16 & 17 & 18 & 19 & 20 \\
\hline \multirow{3}{*}{$\begin{array}{l}\text { accumulative } \\
\text { flushing amount }\end{array}$} & existing scheme & -1268 & -1270 & -1279 & -1258 & -1284 & -1428 & -1409 & -1406 & -1384 & -1403 \\
\hline & $\begin{array}{l}\text { flushing flow } \\
4000 \mathrm{~m}^{3} / \mathrm{s}\end{array}$ & -1412 & -1409 & -1443 & -1416 & -1465 & -1524 & -1511 & -1534 & -1501 & -1521 \\
\hline & $\begin{array}{l}\text { flushing flow } \\
4500 \mathrm{~m}^{3} / \mathrm{s}\end{array}$ & -1471 & -1475 & -1529 & -1491 & -1554 & -1660 & -1628 & -1655 & -1607 & -1675 \\
\hline
\end{tabular}




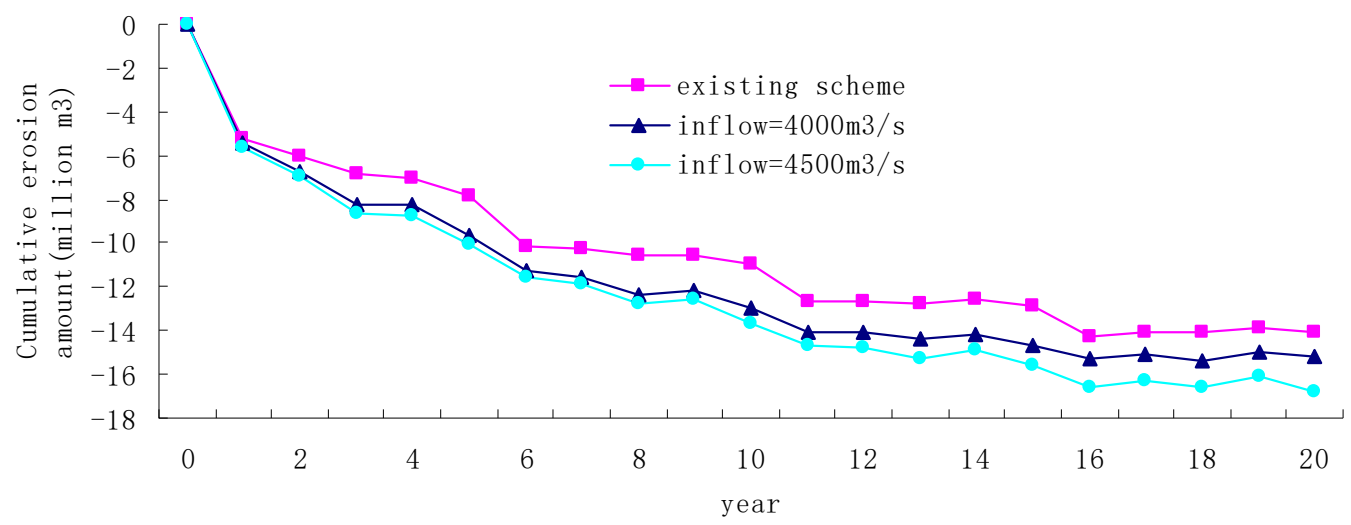

Figure 1. Gongzui reservoir sediment accumulative flushing effects of different schemes

(2) Sediment flushing effect of different schemes of Tongjiezi reservoir

After carrying out flood and sediment joint dispatching schemes, annual maximum flushing amount of Tongjiezi reservoir increases by 0.51 million $\mathrm{m}^{3}$ when flushing flow is $4000 \mathrm{~m}^{3} / \mathrm{s}$, while annual maximum flushing sediment amount increases by 103 million $\mathrm{m}^{3}$ when flushing flow is $4500 \mathrm{~m}^{3} / \mathrm{s}$. Flushing rate improves $4.8 \%$ and $9.7 \%$ respectively. According to a series of water and sediment simulative calculations, Tongjiezi reservoir flushing sediment amount of water and sediment joint dispatching schemes is a little less than that of the existing scheme in the early stage, because in the above two joint dispatching schemes,sediment amount of Gongzui reservoir increases significantly . As time goes on, the accumulative flushing amount of these two joint dispatching schemes is more than that of existing scheme, thus the effect of joint dispatching is shown gradually. After first 15 years, the accumulative flushing amount of joint dispatching schemes will be basically stable, Tongjiezi reservoir will not be back silting anymore. After first 20 years, accumulative flushing amount differences between the two joint dispatching schemes and existing scheme are 3.32 million $\mathrm{m}^{3}$ and 3.72 million $\mathrm{m}^{3}$ respectively. Sediment flushing effects of different schemes for Tongjiezi reservoir are shown in Table 4 and Figure 2.

Table 4 . Tongjiezi reservoir sediment accumulative flushing amount of different schemes

\begin{tabular}{|c|c|c|c|c|c|c|c|c|c|c|c|}
\hline \multicolumn{2}{|c|}{ year } & year & 2 & 3 & 4 & 5 & 6 & 7 & 8 & 9 & 10 \\
\hline \multirow{3}{*}{$\begin{array}{l}\text { accumulative } \\
\text { flushing amount }\end{array}$} & existing scheme & -987 & -1062 & -1039 & -1043 & -973 & -1028 & -990 & -914 & -887 & -806 \\
\hline & $\begin{array}{c}\text { flushing flow } \\
4000 \mathrm{~m}^{3} / \mathrm{s}\end{array}$ & -945 & -977 & -969 & -1003 & -999 & -1113 & -1052 & -971 & -969 & -929 \\
\hline & $\begin{array}{c}\text { flushing flow } \\
4500 \mathrm{~m}^{3} / \mathrm{s}\end{array}$ & -975 & -986 & -1009 & -1033 & -1036 & -1165 & -1107 & -1054 & -1047 & -989 \\
\hline \multicolumn{2}{|c|}{ year } & year & 12 & 13 & 14 & 15 & 16 & 17 & 18 & 19 & 20 \\
\hline \multirow{3}{*}{$\begin{array}{l}\text { accumulative } \\
\text { flushing amount }\end{array}$} & existing scheme & -843 & -786 & -723 & -716 & -651 & -658 & -631 & -610 & -639 & -595 \\
\hline & $\begin{array}{c}\text { flushing flow } \\
4000 \mathrm{~m}^{3} / \mathrm{s}\end{array}$ & -1004 & -954 & -943 & -958 & -937 & -967 & -926 & -925 & -945 & -927 \\
\hline & $\begin{array}{c}\text { flushing flow } \\
4500 \mathrm{~m}^{3} / \mathrm{s}\end{array}$ & -1027 & -983 & -968 & -976 & -937 & -978 & -953 & -966 & -990 & -967 \\
\hline
\end{tabular}




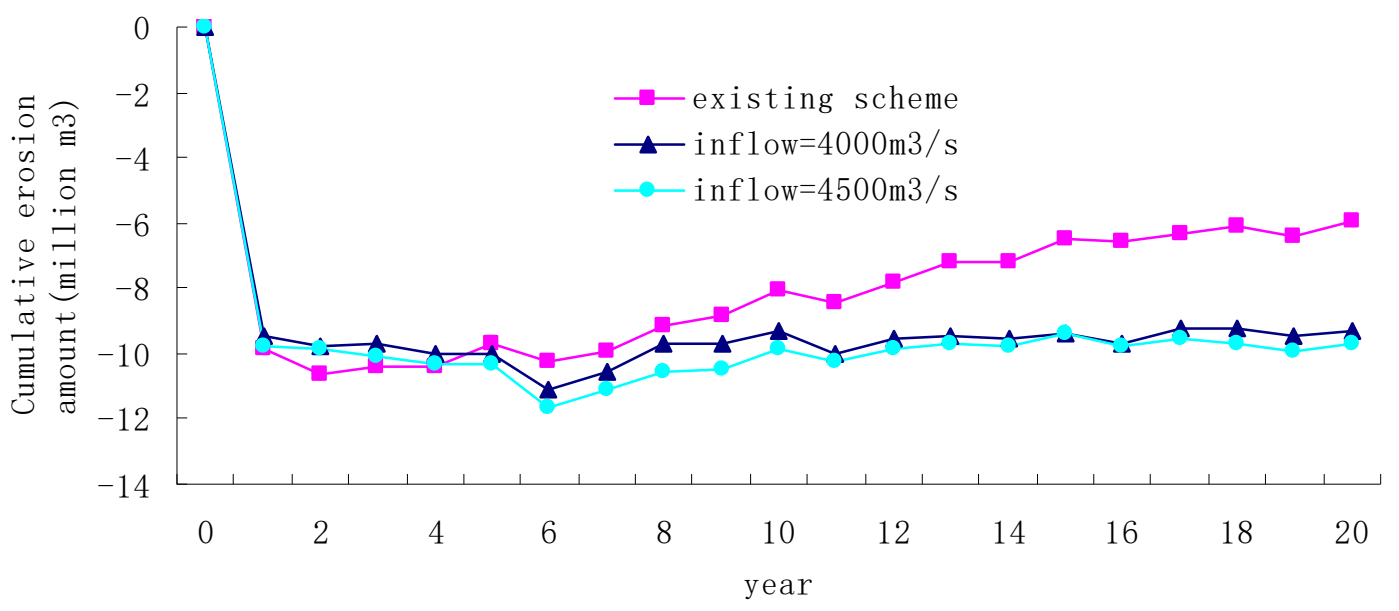

Figure2. Tongjiezi reservoir sediment accumulative flushing effects of different schemes

The effect of Gongzui reservoir and Tongiezi reservoir flood and sediment joint dispatching schemes can be briefly summed up as below.

From the increased proportion of sediment flushing, joint dispatching scheme with flushing flow of $4500 \mathrm{~m}^{3} / \mathrm{s}$ is superior to that of $4000 \mathrm{~m}^{3} / \mathrm{s}$. On the other hand, if the flushing flow is $4500 \mathrm{~m}^{3} / \mathrm{s}$, there will be enough water to open the bottom outlets of Gongzui dam and Tongjiezi dam, without affecting power generation. So it is preferred to carry out the joint dispatching scheme with flushing flow $4500 \mathrm{~m}^{3} / \mathrm{s}$, and lower water levels of Gongzui reservoir and Tongjiezi reservoir to near their dead water levels in time

From the results of simulation, the sediment flushing effect of Gongzui reservoir will not be obvious if we carry out the joint dispatching scheme, because it does not obviously increase flushing times comparing with the existing schemes, and sediment will be less and less. However, the effect of Tongjiezi reservoir joint dispatching schemes will be significant once the sediment deposition phenomenon happens again in the current reservoir running mode.

\section{Summary}

In the paper, based on analysis of sediment deposition of Gongzui reservoir and Tongjiezi reservoir downstream of Dadu river basin, changes of sediment flowing into the two reservoirs are analysed, and flood and sediment joint dispatching schemes of all the reservoirs downstream the river, including Pubugou reservoir, are studied. Effect of each scheme is analysed using reservoir sediment simulation mathematical model. Both the method and the results have clear guiding significance for flood and sediment joint dispatching.

\section{References:}

1. JIN Jian, MA Guangwen,LU Jinbo.Study on power generation plan and water-sediment joint dispatching plan of reservoirs in the lower Dadu river reach $[\mathrm{J}]$. Journal of hydroelectric engineer,2011,30(6): 210-214, 236. (in Chinese)

2. XIONG Min, MA Wenqiong. Sedimentation situation analysis of Gongjiui reservoir $[\mathrm{J}]$. Sichuan Water Power, 2008, 27( S1) : $82 \sim 86$. (in Chinese)

3. HE Xianpei. Sediment control effect and impact on the downstream station of Pubugou reservoir [J]. Sichuan Water Power, 2008, 27( 4): $91 \sim$ 94. (in Chinese)

4. HAN Qiwei, HE Mingmin . Mathematical modeling of reservoir sedimentation and fluvial process [J]. Journal of Sediment Research, 1987, (3) $: 16 \sim 28 . \quad($ in Chinese)

5. XIE Jianheng. River modeling $[\mathrm{M}]$. Beijing: Water Power Press, 1992. (in Chinese) 